\title{
Integrated water resource planning in the city of Cape Town
}

\author{
J. Frame and M. Killick \\ Address?
}

\begin{abstract}
Over the last decade the approach to dealing with an increasing water demand in the Cape Metropolitan Area (CMA) has progressively shifted from a supply oriented philosophy to one where strategies for reducing the demand are integrated with supply management. While there is still much to be done to implement a totally integrated approach, a firm foundation has been laid.

Water demand management as an approach became increasingly prominent in the CCT supply area in the mid 1990s. Accordingly, a Water Demand Management Section was formed in the Water Department of the former Cape Metropolitan Council (CMC). This section was instrumental in shifting the approaches to water demand management in the 6 local councils in the CMA.

Towards the end of 1999 it became increasingly clear that there was a need to adopt an integrated water resource planning approach to manage the future water demand. As a result, the former CMC appointed consultants to carry out an "Integrated Water Resource Planning” (IWRP) study. The results of the IWRP study indicate that a significant saving in water demand could be achieved through the implementation of water demand management initiatives. In comparison to the water supply options, the water demand management initiatives would have a significantly lower implementation cost, could be implemented in a shorter time frame and were generally more environmentally and socially acceptable. Recommendations were made to the new City of Cape Town (CCT) - formed in December 2000 through the amalgamation of the former CMC and the 6 local councils - on where to focus their resources and attention with the aim of meeting and managing the water demand.

The water demand in the CCT has decreased significantly since November 2000. This can be attributed to the recent water restrictions as well as the implementation of water demand management initiatives. The reduction in water demand has delayed the need for the implementation of additional water augmentation schemes other than the Berg Water Project.
\end{abstract}

\section{Introduction}

Water is a scarce resource in the Western Cape, and historically there have been periods of water restrictions followed by the development of new water augmentation schemes. The approach to water supply was very much supply orientated with new water augmentation schemes being developed to meet the growth in water demand.

With the realisation that water demand management was becoming increasingly important in order to ensure future sustainability and affordability, the then Cape Town City Council began with water demand management initiatives 1995. In 1996 as part of the Western Cape Systems Analysis, water demand management was highlighted as one of the twelve options which required further investigation. In 1998 the former Cape Metropolitan Council (CMC) appointed a Manager to oversee Water Demand Management. This was followed by the development of a Water Demand Management Strategy and Policy which was officially adopted and approved by the CMC towards the end of 1998. The need to adopt an integrated approach to water demand management and water augmentation was identified, and towards the end of 1999 the CMC appointed a consortium of Ninham Shand and Arcus Gibb to carry out an "Integrated Water Resource Planning” (IWRP) study.

\section{Background and objectives of the IRWP study}

The aim of the IWRP study was to investigate, at a pre-feasibility

This paper was originally presented at the 2004 Water Institute of South Africa (WISA) Biennial Conference, Cape Town, South Africa, 2-6 May 2004.

学+2721 ; fax: +2721

e-mail: john.frame@capetown.gov.za level, various water demand management initiatives along with 3 water supply options, namely, the Lourens River, the Eerste River and the Cape Flats Aquifer. In order to ensure a more holistic approach, this was extended to include schemes outside the CMA i.e. the Voëlvlei Augmentation Scheme and the Table Mountain Group Aquifer. The study highlighted which initiative(s) should be carried out in order to reduce the demand for water or alternatively increase the supply. Recommendations were to be made on where to focus resources with the aim of managing the water demand and how to initiate an integrated resource planning approach.

\section{Discussion and results of the IWRP study}

The results of the study indicated that a significant saving in water demand could be achieved through the implementation of water demand management initiatives. In comparison to the water supply options, the water demand management initiatives would have a significantly lower implementation cost, could be implemented in a shorter time frame, and were generally more environmentally and socially acceptable. A summary of the options investigated and the overall scoring is given in Table 1.

Based on the IWRP Study, three “packages” were identified for implementation, namely:

- WDM options that can be implemented by the CCT (Package 1)

- WDM options to be implemented by individual consumers (Package 2)

- supply augmentation options to be implemented by the CCT (Package 3)

Package 1 comprises of pressure management, user education, the elimination of automatic flushing urinals, leakage repair and tariffs metering and credit. 
TABLE 1

Summary of options and overall scores

\begin{tabular}{|l|c|c|c|c|c|c|}
\hline Option & Yield & Financial & $\begin{array}{c}\text { Socio- } \\
\text { econ. }\end{array}$ & $\begin{array}{c}\text { Accept- } \\
\text { ability }\end{array}$ & $\begin{array}{c}\text { Environ- } \\
\text { ment }\end{array}$ & $\begin{array}{c}\text { Overall } \\
\text { scores }\end{array}$ \\
\hline Pressure management & 64 & 84 & 62 & 95 & 93 & 83 \\
Elimination of automatic flushing urinals & 57 & 76 & 59 & 94 & 93 & 79 \\
Tariffs, metering and credit control & 69 & 100 & 69 & 29 & 93 & 75 \\
Voëlvlei * & 87 & 83 & 54 & 83 & 51 & 74 \\
Leakage repair & 52 & 64 & 85 & 75 & 93 & 73 \\
Lourens River Diversion & 78 & 84 & 66 & 74 & 44 & 72 \\
TMG Aquifer* & 70 & 75 & 73 & 79 & 39 & 70 \\
Eerste River Diversion & 70 & 75 & 54 & 78 & 53 & 69 \\
Cape Flats Aquifer & 66 & 69 & 57 & 75 & 70 & 69 \\
Treated wastewater for local urban and industrial use & 41 & 75 & 31 & 68 & 97 & 67 \\
Promotion of private boreholes & 38 & 59 & 61 & 74 & 37 & 57 \\
Desalination * & 73 & 25 & 63 & 85 & 82 & 57 \\
Introduction of water-efficient fittings & 48 & 50 & 64 & 38 & 93 & 56 \\
Promotion of grey-water use & 29 & 55 & 28 & 63 & 82 & 54 \\
Treated wastewater for commercial irrigation farmers & 48 & 72 & 10 & 26 & 82 & 51 \\
Treated wastewater reclaimed to potable standard & 71 & 17 & 71 & 38 & 97 & 47 \\
\hline *Options investigated in CMA bulk Water Supply Study & & & & & &
\end{tabular}

Package 2 consists of the promotion of private boreholes, the introduction of water efficient fittings and the promotion of grey water use

The study showed that Packages 1 and 2 needed to be accelerated to reduce the probability of water restrictions prior to the implementation of the Berg Water Project. If the full implementation of these packages exceeds expectations, then future augmentation schemes can be delayed reducing the cost to the consumer and to the environment.

Figure 1 shows the total water demand (urban and agriculture) from the main water resources supplying the Cape Metropolitan Area and the assured supply of those resources. The available supply after 2006 assumes that the Berg Water Project (Skuifraam Dam) has been implemented. The possible reduction in demand, from the no savings scenario, if package 1 and 2 are implemented is also shown. The graph shows that the actual water demand exceeded available supply (at a 98\% level of assurance) in 1999. Should water demand in the urban and agricultural sectors be allowed to grow unrestricted, it would not be possible to supply future water needs in an affordable and sustainable manner and water demand would far exceed assured supply (with no addition of augmentation schemes). With the implementation of effective Water Demand Management initiatives, it is anticipated that a significant reduction in water demand can be achieved.

It is anticipated that Package 3 would consist of the implementation of the Voëlvlei Augmentation Scheme as the next water supply augmentation scheme. In parallel to this it was further recommended that a further feasibility study be carried out on the Table Mountain Group Aquifer, including exploratory boreholes (a pilot Scheme) in order to determine the possible yield and

environmental impacts associated with this potentially valuable water resource. The implementation of Package 3 would increase the available supply to match the projected future water demand with the implementation of Packages 1 and 2. Other future packages which could be considered after package 3 are given in Table 1.

\section{Water demand management initiatives/progress in water demand management}

\section{Water demand}

The IWRP study informed the Water Demand Management(WDM) Policy and the WDM Implementation Strategy which were approved by the Executive Committee in September and October 2001 respectively. Evidence suggests that significant savings can be achieved and the strategy document therefore set as a target the reduction in the projected 2010 demand of $20 \%$. This is below the 


\section{Bulk Water Supplied by the CCT}

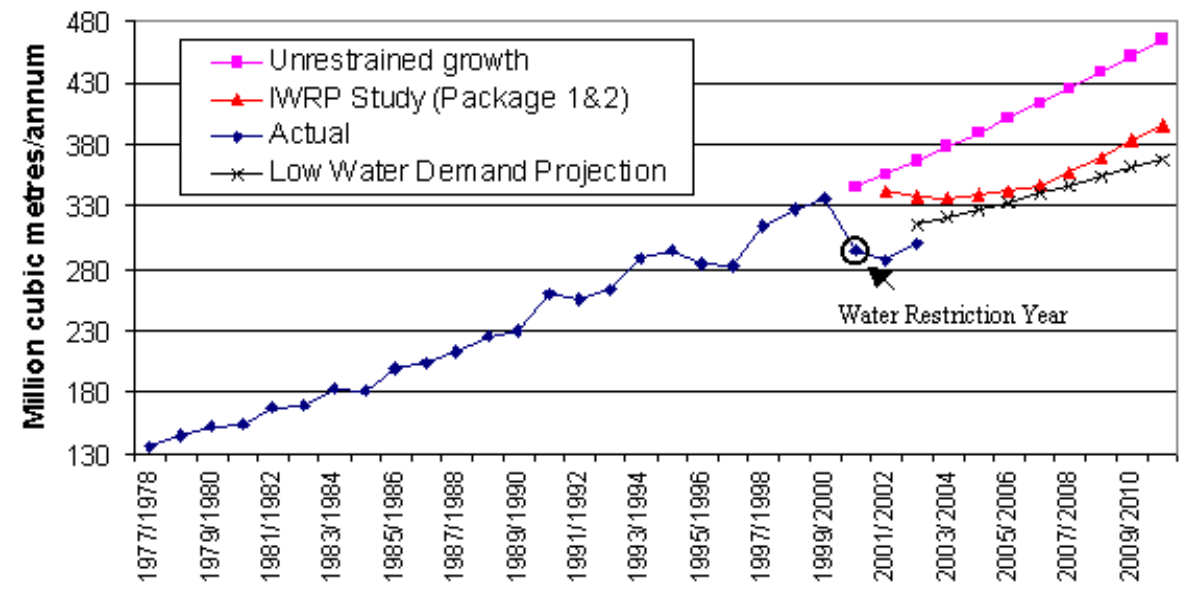

demand curve estimated by the implementation of packages 1 and 2 described in the IWRP study (see chart above). An encouraging sign is that at the end of the 2002/03 financial year the demand was already $18 \%$ below the projected unconstrained demand. This reduction could possibly be attributed to a combination of the lingering affects of the 2001/02 restrictions, the retention of the restriction on garden watering between 10:00 and 16:00, WDM measures already implemented, tariff increases on 1 July 2001 and possible weather effects. A recent customer/citizen survey showed that $57 \%$ claim to have changed their behaviour with respect to water usage; $41 \%$ of these due to higher tariffs, $32 \%$ due to water restrictions.

A study to assess and review the potential growth in long term water demand has recently been commissioned.

\section{WDM policy}

The WDM Policy is based on three broad principles namely that water is a strategic, precious and scarce resource; that the wastage of water shall not be tolerated; and that all consumptive water use shall be measured and accounted for. There has been extensive political and administrative buy-in to these principles.

Long-term objectives set out in the policy include equity; sustainability; affordability; promotion and, where appropriate, legislate the optimal use of water; maximise the use of alternative sources; minimise the loss of water; and ensure wise use of water by the municipality. The issues of equity, affordability and sustainability have informed free basic water and the five-step tariff. The five-step tariff is an excellent WDM measure as it provides a financial disincentive to those who consume higher quantities to reduce their consumption. Free basic water of $6 \mathrm{Kl}$ per month ensures that the poor have access to water.

As water demand management becomes increasingly successful through WDM measures including tariffs, the issue of the tariff structure and pricing of each step will become increasingly critical not only to ensure equity, affordability and sustainability but also to ensure that income and expenditure are adequately balanced. A situation that is not well managed could result in a shock to the tariff.

\section{WDM Strategy}

Circumstances have changed since the existing WDM Strategy was adopted by Council in October 2001 and it is therefore under review. This review will be finalised by November 2003. The existing WDM Implementation Strategy was developed to ensure that the policy was put into effect. Through a process of workshops strategic objectives were identified. From the outset it emerged that there was a need to further raise the profile of water demand management. It was believed that this could be done through identifying champions amongst the politicians, clarifying the roles of managers with respect to WDM and ensuring that managers incorporate WDM into their business plans. Further objectives set include Package 1 and Package 2 initiatives (IWRP) i.e.:

- Package 1: pressure management, user education, the elimination of automatic flushing urinals, targeted leakage repair in low-income areas, optimisation of tariffs and universal metering and credit.

- Package 2: promotion of private boreholes, the introduction of water efficient fittings (By-laws and national performance standards through SABS) and the promotion of grey water use

Other objectives are the implementation of a bulk meter management system ("to measure is to know"); and the development of a municipal WDM policy.

Package 1 initiatives scored highest in the IWRP study, are more 'favourable' and therefore initially more emphasis has been placed on these initiatives, although work continues on package 2 and other WDM measures.

\section{Raise the profile}

The profile of WDM has been raised significantly. Key politicians responsible for Water Services have been identified as champions and attend such events as Water Week. The City's WDM section was well represented at the World Summit for Sustainable Development held in Johannesburg in August 2002. The City has won two awards; the Green Trust Award for the 2000/01 water restrictions campaign and the South African Institution of Civil Engineers National Technical Excellence Award for the Khayelitsha Pressure Management Project. Managers are responsible for motivating and managing WDM projects. WDM will be a key performance indicator for all relevant managers when the performance management system is rolled out to all management levels.

\section{Package 1 progress}

The implementation of pressure management was given a substantial boost by the successful implementation of the Khaylelitsha Pressure Management Project. It has resulted in savings of between 2 to $3 \%$ of the city's water demand. An added benefit of this project has been the delay in the extension of the Zandvliet Wastewater Treatment Plant. A pressure management system is near completion in Site C, Khayelitsha and another is planned for Mfuleni. 
Following the successful 2000/01 water restrictions campaign, user education has continued albeit at a lower level of intensity. There have been numerous adverts and newspaper supplements, water week activities, marketing at the World Summit, the Schools Awareness Programme and joint education drives with the city departments. Water Week 2003 was for the first time a joint effort between the Department of Water Affairs and Forestry (DWAF) and Cape Town Water Services. The effectiveness of these activities has been measured in the annual customer survey. The survey showed that of the $57 \%$ of those surveyed, $28 \%$ changed their behaviour with respect to water usage by becoming more aware of the issues. A survey done in December 2001 after the water restrictions campaign showed that the most effective media is newspapers.

The Schools Awareness Programme is likely to step up a gear as the Directorate explores more formal partnership arrangements with the Department of Education. As a first step in this process, an audit of all schools, which includes implementing some immediate WDM measures, was carried out in the first half of 2003. The iKapa water leaks project which started in 1998 and completed during 2001/2 continues to save $1.8 \%$ of the city's annual water demand on a continuous basis. A similar project in Masimphumelele started in 2000 has resulted in a reduction in water demand in that area of 58\%. The Khayelitsha Water Leaks Project started in 2001/02 and is ongoing.

A substantial amount has been spent on zone metering and telemetry which will assist city officials to identify other WDM projects. On an ongoing basis, gallon meters are being replaced and meters installed where they do not exist or are faulty.

Effective credit control was identified as a major driver for WDM. However, due to a moratorium from the new Council it has been put on hold. Once a new Indigent Policy has been adopted, it is expected that credit control will be vigorously pursued with the benefit of reducing the water demand. From the customer/citizen survey it is clear that the city wide implementation on 1 July 2001 of the five step-tariff has had a significant effect in the reduction in water demand as parts of the city had significant increases. The implementation of free basic water (6Kl) in May 2001, and a free sanitation allocation $(4.2 \mathrm{Kl})$ and a R20 rebate for water and sanitation for households with property values below R50 000 in July 2002 should make credit control easier to implement and more acceptable for the politicians. Measures like this should further promote WDM.

The programme for the removal of automatic flushing urinals (AFUs) continues. Mechanisms are being explored as how to speed up the process of identification and removal of these water-wasting devices.

\section{Package 2 progress}

Significant progress has been made in developing components of a Water Services By-law. A By-law to limit or restrict the use of water was submitted to and approved by Council in March 2002. This empowers Council to enforce restrictions and other WDM measures. The restriction on not watering gardens between 10:00 and 16:00 was retained when the restrictions were lifted in October 2001. The Wastewater and Industrial Effluent By-law is in draft form and will be submitted to Council soon. These and other Bylaws will eventually be combined into one Water Services By-law. In line with promoting the use of private boreholes, existing registered boreholes and wellpoints have been mapped, but there are major discrepancies due to incorrect information from the public. In a joint venture with the Catchment, River and Stormwater Management Department a study will commence shortly on map- ping of groundwater in the CMA to assist the public with information as to the location, quality, expected yields and depth of these sources.

\section{Other initiatives}

A water management system has been fully implemented in one of the administrations and partially in others. This system allows managers to identify the areas where losses are occurring as well as where there are abnormal or zero consumptions (i.e. meters not read). This will improve knowledge of the city's water network and consumption patterns and result in a more targeted approach to WDM.

The upgrading and extension of the Bellville Wastewater Treatment Plant treated effluent supply is almost complete. This demonstrates the seriousness with which the city is tackling WDM.

To ensure that the City 'practices what it preaches', a database of all municipal buildings, sportsfields and parks is being compiled and mapped onto GIS (Geographical Information Systems). Such information as consumption patterns, use and availability of alternative sources, and other relevant information will be contained in this database. This database will assist municipal officials to target priority projects and to monitor the effectiveness of our internal WDM initiatives.

Assistance to others in the region continues. The City has assisted Drakenstein and Stellenbosch Municipalities and the West Coast District Council with such measures as pressure management, telemetry systems and user education. Drakenstein and Stellenbosch, being supplied with bulk water from the city's system currently pay a levy as part of the bulk tariff to fund these measures.

\section{Commitment and budget}

The City budgeted approximately R22 million (capital and operating) in 2002/03 on direct WDM measures and is committed to making WDM work. Budget constraints have resulted in this expenditure being reduced to R18 million. This change in budget allocation has necessitated the revision of the WDM Strategy mentioned previously. The five-year budget for WDM is outlined in the Water Services Development Plan, but will need to be revised. It is likely that as more is learned about the water network and the relative effectiveness of the various WDM measures, the budget commitment will be reviewed as part of an ongoing process of strategy review. The learning process should result in an optimum expenditure for WDM. Little is known currently as to what this optimum is.

\section{Water augmentation schemes}

\section{The Voëlvlei augmentation scheme}

Should the City achieve its objectives as set out in its Water Demand Management Strategy and dependent on the growth in water demand by other users, a new water augmentation scheme would only be required by approximately 2012. At this stage it is anticipated that the Voëlvlei augmentation scheme would be the next major augmentation Scheme to be implemented after the Berg Water Project (the Skuifraam Scheme ).

Prior to implementation there are further studies which have to be timeously carried out. These Studies include inter alia:

- Establishment of estuary requirements and reserve determination

- Water quality and water treatment options 
Table Mountain Group Aquifer

In accordance with the recommendations contained in the CMA Bulk Water Supply Study, the City of Cape Town called for proposals from consultants to assist the CCT in conducting a feasibility study and pilot project on the Table Mountain Group Aquifer.

The City of Cape Town appointed the TMG Aquifer Alliance in April 2002 to carry out the feasibility study and pilot project. The objectives of the feasibility study are to determine the possible yield and environmental impacts associated with this potentially valuable water resource. It is anticipated that the project will take approximately 5 to 6 years. It is envisaged that this study and pilot project will enable City to make an informed decision about the long term sustainability, economic benefits and environmental impacts of the exploitation of the TMG Aquifer.

\section{Other related studies}

\section{Reuse of treated effluent}

Whilst the reuse of treated effluent was not part of Packages 1, 2 or 3 , the City viewed it as important to further investigate this option. A study was therefore initiated to refine the pre-feasibility waste water reuse proposals contained in the IWRP study, as well as collate and map all the existing information in the Cape Metropolitan Area pertaining to the reuse of treated effluent for industrial and irrigation purposes.

The Study further commented on: required standards, problems associated with effluent reuse and waste water reuse practises elsewhere in the world. Recommendations on issues which need to be studied in more detail were also made.

\section{Water services development plan (WSDP)}

The WSDP was approved by the Executive Committee of Council in April 2002. This document includes further information on the IWRP, WDM and the various supply options being considered. The approved document can be accessed on the City's website: www.capetown.gov.za/water/wsdp

\section{Conclusion}

In order to alleviate the pressure on the current available water supply sources and reduce the risk of imposing ever increasingly severe water restrictions, the implementation of all of the water demand management initiatives in both packages 1 and 2 are being accelerated. In addition to this, the planning and implementation of additional water supply schemes (Package 3 ) have commenced.

There are clear indications that the WDM policy and strategy (process started in 1998) are producing the desired results, at least when one examines trends. While there is some concern about the accuracy of the metering and billing systems at the moment, the Unaccounted for Water for the 2001/02 financial year was 18\%, down from $22 \%$ in the previous financial year. While the factors influencing the current $18 \%$ reduction in projected unconstrained demand still need to be better understood, it does give an overall indication that the WDM measures are having some effect. The customer/citizen survey showed that $57 \%$ of respondents have changed their behaviour due to the implementation of the WDM strategy. The $1.8 \%$ ongoing savings as a result of the iKapa Leaks project, started in 1998, and other WDM measures have had a significant influence on the slowdown in water demand trend.

While WDM measures in comparison to the water supply options "have significantly lower implementation cost, could be implemented in a shorter time frame and were generally more environmentally and socially acceptable”, much still needs to be learned practically about the relative effectiveness of the various measures. As knowledge of the influence on water demand of, for example, user education and tariffs improves, water demand management as a component of integrated water resource planning will become more sophisticated with increasing benefits to the users and the environment.

The benefits of achieving optimal integrated water resource planning, and the implementation thereof, will assist in keeping water affordable, sustainable and minimise the impact on the environment by delaying future water augmentation schemes.

\section{References}

Water Demand Management Policy of the City of Cape Town. September 2001.

Water Demand Management Implementation Strategy of the City of Cape Town. October 2001.

Water Services Development Plan of the City of Cape Town. June 2002.

City of Cape Town. Progress Report on Water Demand Management for 2001/2002.

Ninham Shand, Arcus Gibb. 2001. Integrated Water Resource Planning Study. 